\title{
Satire en politiek incorrecte taal: de premie op taboe-doorbreken
}

Bas van Stokkom

Verschenen in Tijdschrift over Cultuur \& Criminaliteit 2015, 5 (3): pp. 73-83

Satire beoogt taboes te doorbreken. Dat is een geliefd spel geworden bij politiek incorrecte sprekers. Zij ijveren voor een absolute vrijheid van meningsuiting en alles wat naar een Gedachtenpolitie zweemt is verdacht. Opvallend is dat politiek rechts deze stijlvormen van links lijkt te hebben overgenomen. In deze bijdrage zal ik dieper ingaan op deze wonderlijke rolverwisseling: rechts presenteert zich als libertair en opstandig, links wordt neergezet als conformistisch en regentesk. Ik zal betogen dat taboe-doorbreken nog altijd een effectief middel is om de definitiemacht te vergroten en de gevestigde instanties in diskrediet te brengen. Maar ik poog ook aan te geven dat de retorische strijdmiddelen in hun tegendeel kunnen omslaan. In het slechtste geval, zegt de Britse schrijver Tim Parks, versterkt satire een intellectuele houding die het juist wenste te ondermijnen: fanatiek ten strijde trekken en nieuwe taboes propageren. ${ }^{1}$

Ik zal eerst de commotie rondom de cartoons van Charlie Hebdo bespreken en vooral inzoomen op de strijdbare pleidooien voor maximale artistieke vrijheid, onder meer verwoord door Salman Rushdie. Vervolgens komen enkele kritieken op deze opvattingen aan bod. In het tweede deel van dit essay betoog ik dat pleitbezorgers van een onaantastbaar recht op vrije meningsuiting, inclusief een recht te beledigen, hun eigen taboesfeer creëren. Binnen de schandaalindustrie krijgt dit recht echter geheel andere functies. Tenslotte vestig ik de aandacht op enkele dubbelzinnigheden rondom politieke correctheid en het racisme-taboe. Ik herneem daarmee deels de kritiek verwoord in Mondig tegen elke prijs (2007). Ik zette daarin uiteen dat het vrije woord dienst doet als nieuwe fetisj: een verafgoding van onbelemmerde zelfexpressie en het doorbreken van welk taboe dan ook. Het recht om te bespotten of kwetsen en het openbaar maken van vulgaire of liederlijke gedachten zou de kwaliteit van de democratie enkel kunnen vergroten. Ik betoogde dat het hier om een bijgeloof gaat 'dat aan elke uiting magisch positieve eigenschappen toeschrijft'. Verder zette ik uiteen dat de deugd van vrijmoedig spreken vanouds gericht is tegen machtige partijen (inclusief de publieke opinie) en in het teken staat van een 'dienend ethos': de vrijmoedige ziet het als zijn plicht tirannen, geestelijken en andere machthebbers te kritiseren maar ook om gewone mensen op weg te helpen. Dit essay bouwt voort op die gedachten.

\section{Taboe, satire en cartoon-affaires}

De term taboe had oorspronkelijk - in de Polynesische betekenis - betrekking op religieuze onderwerpen die zo heilig werden geacht dat er niet over gesproken kon en mocht worden. In zekere zin is dat nog steeds het geval. Kannibalisme, incest, pedofilie, coprofagie en necrofilie: onze moraliteit verzet zich er vierkant tegen. Deze praktijken vinden we walgelijk

\footnotetext{
${ }^{1}$ Tim Parks, The limits of satire, The New York Review of Books, January 16, 2015 http://www.nybooks.com/blogs/nyrblog/2015/jan/16/charlie-hebdo-limits-satire/
} 
en verdorven en worden in 'beschaafde gezelschappen' niet besproken (Allan \& Burridge, 2006).

De typen en vormen van taboes zijn in de loop van de geschiedenis aanzienlijk veranderd. Aanvankelijk vooral gerelateerd aan het heilige en de definitiemacht van prelaten, zijn taboes momenteel sterk gerelateerd aan alles wat indruist tegen (vol) leven en gezondheid: dood, pijn, slachten, martelen, ziekte, lichamelijke afwijkingen, lelijk of gehavend uiterlijk. Racisme is een relatief jong taboe, gerelateerd aan de democratische diskwalificatie van gevoelens van superioriteit en inferioriteit (Wouters, 2008).

Machtige groepen poogden vanzelfsprekend uitingen in de taboesfeer te houden, of het nu atheïsme was of oproepen tot staatsgevaarlijke activiteiten. Er moest desnoods flink censuur worden uitgeoefend. In de moderne tijd, en zeker vanaf de jaren zestig, is censuur haast per definitie verdacht geraakt en is het een sport geworden taboes te doorbreken. Alle heilige huisjes moeten onderuit. Een taboe doorbreken heeft een choquerend effect en als het een taboe van een politieke tegenstander betreft, staat dat garant voor veel opschudding en strijd. Het schaadt het aanzien van je opponenten en verleent definitiemacht. Satire is daarbij een beproefd middel.

Religie duldt geen satire of aanstootgevende literatuur waarin het heilige boek wordt bezoedeld. Klassiek is de fatwa die over Salman Rusdie werd uitgesproken nadat De duivelsverzen (1989) waren verschenen. Ayatollah Khomeini veroordeelde Rushdie en de uitgevers van zijn werk bij verstek tot de dood. Hij verwoordde dat als volgt: "Ik roep alle dappere moslims waar ook ter wereld op om hen zonder vertraging te vermoorden, zodat niemand daarna nog het heilige geloof durft te beledigen." ${ }^{2}$ Een illustratie van primitieve vergeldingsdrang en afschrikkingsgeloof tegelijk. Zoals bekend, sinds 1989 is de schrijver ondergedoken. Hij is een hartstochtelijk pleitbezorger van de volle vrijheid geworden, maar is gaandeweg verbitterd geraakt. Hij begrijpt niet dat schrijvers en intellectuelen niet voor de volle honderd procent het vrije woord verdedigen. Volgens Rushdie kunnen literatuur en fictie niet beledigen. Ook na de Charlie Hebdo-affaire liet hij van zich horen. Hij vindt het onbegrijpelijk dat velen - links of rechts - bedenkingen ventileren ten aanzien van het satirische blad, of het nu vuilspuiterij of racisme is. 'Vrijheid is ondeelbaar', zegt Rushdie. Kunstenaars en schrijvers hebben de plicht de grenzen op te zoeken. De 'forces of utterance' vinden steeds de 'forces of censorship' tegenover zich. Het vrije woord inperkingen opleggen of toegeven aan nuanceringen is gevaarlijk voor kunstenaars. Zij hebben de plicht daarin niet mee te gaan, hoe moeilijk dat ook is. ${ }^{3}$

Rushdie en vele anderen schrijven Charlie Hebdo een heldenrol toe. De cartoonisten lieten zich niet intimideren en figureren als kampioenen van het vrije woord. Ook Mark Rutte deed een duit in het zakje. Volgens de premier is bijtende spot 'het wezen van de democratie en tegelijkertijd de kern van echte vrijheid'. ${ }^{4}$ De meest heilige zaken moeten voorwerp kunnen zijn van kritiek, spot en satire.

\footnotetext{
${ }^{2}$ Zie Rutger van der Hoeven, 'Mensen geven niet om kunst'. Romans die onze blik veranderden Salman Rushdie - De duivelsverzen. De Groene Amsterdammer 3 september 2015.

${ }^{3}$ Guardian 15 januari 2015.

${ }^{4}$ Zie de toespraak bij de manifestatie voor steunbetuiging aan de slachtoffers en de nabestaanden van de terreuraanslag in Parijs, 8 januari 2015. https://www.rijksoverheid.nl/actueel/nieuws/2015/01/08/rutte-handen-afvan-onze-vrijheid. Als het gaat om vrije meningsuiting neemt de 'pragmaticus' Rutte regelmatig een absoluut
} 
Tijdens de tumultueuze discussies die op de aanslag volgden, wemelde het van de strijdlustige slogans. Zo zou godslastering bijdragen aan het grotere goed van een vrije samenleving. Sommigen claimen zelfs een 'heilig recht op heiligschennis', ${ }^{5}$ zoals Hirsi Ali eerder al een 'liberale Jihad' claimde. Volgens sommigen is het beste antwoord op de aanval op Charlie Hebdo 'om godslasterlijke satire te laten escaleren'. ${ }^{6}$ Het gaat erom ten strijde te trekken en zoals Rushdie het zegt - alle religies te onderwerpen aan 'fearless disrespect'.

\section{Enkele kritiekpunten}

Ik heb de indruk dat de rol die satire krijgt toebedeeld, wordt overschat. Je krijgt de indruk dat de vitaliteit van de democratische samenleving geheel en al afhangt van oneerbiedige uitingen en het belachelijk maken van de Islam. Het was op zich al verbazend dat veel opiniemakers zich identificeerden met een tijdschrift dat zelf 'journal irresponsable' als motto had verkozen. Maar bovenal roept het gemak waarmee een absolute vrijheid van meningsuiting wordt ingeroepen, verbazing op. Ik zal twee kritiekpunten bespreken. De eerste heeft betrekking op hypocrisie, de tweede op het bespotten van machtigen.

De Amerikaanse columnist Glenn Greenwald ${ }^{7}$ werpt de volgende retorische vraag op: als religie geen respect verdient, moeten we het Joodse geloof dan ook bespotten? De westerse gemeenschap stoot in dat geval op een immens taboe. Niet verwonderlijk, zegt Greenwald, dat veel kruisvaarders van het vrije woord hier halt houden en de publicatie van antisemitisch materiaal ontraden. Sterker, dergelijke dweperij wordt sterk veroordeeld. Zelfs Charlie Hebdo ontsloeg een cartoonist vanwege antisemitisme. Om die reden spreekt Greenwald over hypocrisie. Pleitbezorgers van het opvoeren van de godslastering-machine hebben een speciale voorliefde voor het bespotten van de Islam. Van een gelijke kans bespot te worden is geen sprake. Greenwald voegt er fijntjes aan toe dat vergelijkingen trekken tussen IS en de staat Israël bij menig strijder voor 'more speech' a priori als een Gedachten Misdaad geldt. De vraag is dus welke heilige dingen bespot mogen worden. Vermoedelijk zal geen enkele krant het in zijn hoofd halen de 'satirische' Duitse cartoons over de Jodenvernietiging te publiceren. Dat leert dat veel vrijdenkers selectief te werk gaan en vooral de inferioriteit van de Islam bevestigd willen zien.

De bekende Britse cartoonist en schrijver Martin Rowson beaamt dat satire aanstoot moet geven. Wat dat betreft bevindt visuele satire zich in het zelfde rijk als het taboe: het gaat om 'deep, dark magic', een soort voodoo, omdat een karikatuur doelbewust reputaties beschadigt door het slachtoffer in iets anders te doen laten veranderen, en wel zodanig dat zijn ziel wordt gestolen (Rowson, 2009: 153). Karikaturiseren is dus zowel een overtredende als een

standpunt in. Zo haalde hij de omstreden spotprenten van Nekschot (o.a. Anne Frank copulerend met de profeet Mohammed) naar de Tweede Kamer.

${ }^{5}$ Rama Yade (8 januari 2015), Le droit au blasphème est une droit sacré, Opinion Internationale. http://www.opinion-internationale.com/2015/01/08/rama-yade-le-droit-au-blaspheme-est-un-droitsacre_32717.html

${ }^{6}$ Zie Glenn Greenwald (9 januari 2015), In solidarity with the free press: some more blasphemous cartoons https://theintercept.com/2015/01/09/solidarity-charlie-hebdo-cartoons/

${ }^{7}$ Idem. 
agressieve handeling. Maar Rowson is bepaald geen voorstander van onbeperkte satire. Satire is zijn inziens het bespotten van machtigen.

"I see my job as giving targeted offence, because satire, to borrow HL Mencken's definition of journalism, is about comforting the afflicted and afflicting the comfortable. In other words, if I draw rude pictures of people less powerful than myself, what I do ceases to be satire, and creeps into one of the wider sphere of aggressive, bullying humour and into areas I consider offensive." (2009: 150)

Het komt er dus op aan sociaal en politiek hoger geplaatsten te bespotten. Het gaat volgens Rowson om een boodschap, een punt maken. Sick jokes zijn uit den boze, net als agressieve of smakeloze aanvallen die niet grappig zijn. Dan wordt een cartoon louter propaganda. Zie de anti-Joodse haatcartoons van Der Stürmer. ${ }^{8}$

Het zal niet verwonderen dat Rowson weinig op heeft met de cartoon-actie van de Deense conservatieve krant Jyllands-Posten in 2006. ${ }^{9}$ Het was de intentie van de krant een specifieke groep mensen te verontrusten, 'a group of isolated, beleaguered, powerless and poor people in Danish society, many of whom probably also clean the lavatories and empty the bins at Jyllands-Posten's offices' (2009: 162). De krant voldeed bepaald niet aan de Mencken-test, hoewel - zo voegt hij er aan toe - de antwoorden van machtige Islamitische geestelijken in Denemarken en regeringen in het Midden Oosten de publicatie van de cartoons achteraf bijna rechtvaardigden.

Overigens, Flemming Rose, de redacteur die de beruchte cartoons publiceerde, zei herhaaldelijk dat het niet de bedoeling was aanstoot te geven en dat de cartoons geen aanleiding gaven moslims te stereotyperen. "We are integrating you into the Danish tradition of satire because you are part of our society, not strangers." (geciteerd in Rolfe, 2008: 272). Zijn logica volgend zouden moslims flink hebben gelachen om de cartoons, in het besef opgenomen te zijn in de Deense familie. Overigens had Jyllands-Posten eerder geweigerd Jezus-cartoons te publiceren omdat die christelijke lezers zouden kunnen shockeren.

\section{Het absolute recht te uiten wat je wil}

De aanslag op Charlie Hebdo bracht dezelfde reflexen voort als de Deense cartoon affaire. De agressie en intolerantie binnen de radicale Islam worden beantwoord met liberale vormen van woede en scherpslijperij. De controverse openbaart een botsing van taboes en een dialoog van doven: twee onbuigzame kampen die louter tot hun eigen achterban preken. De taal van absolute waarheden - de dweperij met de profeet en het verlangen religieuze satire in een hogere versnelling te brengen - vereist dat je geen strobreed toegeeft.

Veel liberale en libertaire geesten geloven in de zegeningen van het vrije woord en je krijgt de indruk dat 'alles zeggen' voor provocerende opiniemakers sacrosanct is geworden.

Omgekeerd kan censuur in hun ogen nooit gerechtvaardigd zijn. Dat suggereert dat alle resterende taboes onder verdenking staan. In zekere zin wordt het taboe zelf taboe verklaard:

\footnotetext{
${ }^{8} \mathrm{Zie}$ http://research.calvin.edu/german-propaganda-archive/sturmer.htm

${ }^{9} \mathrm{Zie}, \mathrm{https} / / / \mathrm{www}$. youtube.com/watch?v=vbbfxZOyw8U
} 
stilzwijgen en toedekken voelen als een bezoedeling van het vrije woord. Daarom roept vooral zelfcensuur veel weerzin op: je genuanceerd uitdrukken zou getuigen van hypocrisie en gebrek aan moed. Zelfcensuur krijgt zelfs de betekenis van een karakterfout: 'buigen' voor de vijand die juist beledigende kritiek verdient. Dat de zelf-censor vrijelijk kan besluiten om een gematigd standpunt in te nemen wordt gemakshalve vergeten.

Binnen dit militante liberalisme claimen velen een 'recht te beledigen', in Nederland bijvoorbeeld Afshin Ellian, Leon de Winter en andere 'vrienden van Theo van Gogh'. Of de discussie daardoor op scherp wordt gezet zoals zij menen, is de vraag. Het gaat vaak louter om sarrende bewoordingen, een retorische strijd die vooral de eigen superioriteit moet bevestigen. Een 'recht te beledigen' kan dan ook worden begrepen als een 'recht van de sterkste', voorbehouden aan goed gebekte opiniemakers die er lol in hebben groepen burgers op stang te jagen.

$\mathrm{Nu}$ zijn provocateurs aangewezen op een maximaal speelveld, maar op de markt van expressieproducten heeft het onbelemmerde vrije woord andere functies verkregen. Obscene beelden en verdachtmakingen verzekeren geëmotioneerd vervolgnieuws. Er zijn grote commerciële belangen mee gemoeid. Mede daarom zijn schandaalbladen, talkshows en shocklogs verzot op relletjes en hebben ze een voorliefde voor de beschuldiging. In Nederland doen de rebelse onderafdelingen van de Telegraaf veel moeite reputaties te slopen en autoriteiten aan de schandpaal te nagelen. Met enige regelmaat weet GeenStij1 woedecollectieven en beschamingsmeutes op de been te krijgen (Van Stokkom, 2013). In Engeland is The Sun niet afkerig van 'batter a burglar'-campagnes.

Opmerkelijk is, zegt de Britse filosofe Onora O’Neill, dat het in de commerciële pers en media niet zozeer gaat om de bijdrage aan meningsvorming. Terwijl in de negentiende eeuw het vrije woord nog werd gezien als voertuig voor rechtvaardigheid en emancipatie van zwakkere partijen, staat meningsuiting nu veeleer in het teken van provocerende nieuwsproducten. Niettemin menen voorstanders van maximale uitingsvrijheid de machtelozen van dienst te zijn wanneer de markt uitingen onbelemmerd aan de man kan brengen. ${ }^{10}$

Illustratief is hoe de Murdoch-bladen de wetenschappelijke 'consensus' over de opwarming van de aarde bestrijden. Het mediaconsortium keert zich tegen de wetenschappelijke 'elite' die geen afwijkende meningen duldt en in feite is overgegaan tot censuur. Aldus kunnen Murdoch-reporters - van Sunday Times tot FoxNews - zich presenteren als dissidenten die de moed hebben het vooringenomen wetenschapsbastion te ontmaskeren (McKnight 2012: hoofdstuk 9).

In de schandaalpers is beschuldigen van censuur een tweede natuur geworden. Tegelijk fungeert het vrije woord regelmatig als excuus voor journalistieke intimidatie, inbreuken op privacy en agressief bejegenen van mensen die iets te verbergen hebben. Arrogante bestuurders, dwaze beroemdheden en kwaadwillende lieden verdienen immers geen respect. Journalistieke ethiek wordt in een adem door als 'socialisme' of staatsinmenging afgedaan. ${ }^{11}$ Vooral in de Angelsaksische wereld loopt de zogenaamde 'vrije pers' meer en meer aan de leiband van mediabaronnen en hun machtsbolwerken. Alleen daarom al is het de vraag

\footnotetext{
${ }^{10}$ Zie Onora O'Neill, A right to offend? Guardian 13 February 2006.

${ }^{11}$ Voor de criminele werkwijze van The News of the World zie Dean 2013
} 
waarom die monopolisten over onvoorwaardelijke vrijheid van expressie dienen te beschikken. Waarom zouden zij het onbeperkte recht moeten hebben om reputaties kapot te maken, minderheden te intimideren, slachtoffers te belagen of in diskrediet te brengen zoals de Britse ouders McCann, of het Amerikaanse volk een Irak-oorlog aan te praten? ${ }^{12}$ Alles zeggen en beweren en lak hebben aan de feiten culmineert binnen die mediasyndicaten regelmatig in agressie, opruiing en misleiding en de gevolgen daarvan zijn vaak niet te overzien.

\section{Politieke correctheid}

De dagelijkse agitatie rondom kwetsen en gekwetst worden en het gevoel dat vrijuit spreken gedwarsboomd wordt door allerlei gevoeligheden - van zwarte Piet tot vermeend etnisch profileren - geeft de indruk dat de vrijheid van meningsuiting onder grote druk staat. Libertaire geesten komen vaak woorden tekort om de aantasting van het vrije woord te schilderen. In Nederland doet onder meer Henri Beunders, hoogleraar ontwikkelingen in de publieke opinie aan de Erasmus Universiteit, regelmatig pogingen om het tragische einde van het vrije woord te duiden. Volgens hem is 'de citadel van de kritische geest, van het vrije debat, al bijna ingestort'. ${ }^{13}$ De socioloog Frank Furedi - analyticus van de angstcultuur vreest dat steeds meer beledigden hun critici het zwijgen zullen opleggen. De verboden breiden zich gestaag uit en het zal steeds moeilijker worden om open discussies te organiseren 'over kwesties die hardliners onder de beledigden als aanstootgevend ervaren'. ${ }^{14}$ Deze zorgelijke meningen lijken sterk op de klachten van populisten en de schandaalpers dat je 'tegenwoordig' - door de taboes van politieke correctheid - niet meer over migratie kunt spreken, terwijl de kranten, praatprogramma's en blogs onophoudelijk issues uit de stal van de identiteitspolitiek onder de aandacht blijven brengen.

Dat brengt me bij de thematiek van politieke correctheid en de gevolgen ervan. Politiek correct was oorspronkelijk een sarcastische frase die Amerikaanse communisten gebruikten voor partijgenoten die onvoorwaardelijk vasthielden aan de partijlijn, ongeacht de morele en politieke inhoud ervan (Hughes, 2009; Hildebrandt, 2005). In de jaren zestig nam de nieuw linkse beweging die de scepter zwaaide over de Amerikaanse universiteiten, dat sarcasme over. De term werd ook benut als zelfkritische satire om non-conform gedrag van medestudenten te bespotten. Zo werd stoppen bij McDonald's of een seksistisch grap beantwoord met 'Not very "politically correct", Comrade!' (Hughes, 2009: 74). Het begrip werd gaandeweg ook door studenten ingezet tegen multiculturele academici. In termen van de classicus Roger Kimball: "Politically correct described the self-righteous, non-smoking, ecological sensitive, vegetarian, feminist, non-racist, sandal-wearing beneficiaries of capitalism... who paraded their outworn sixties radicalism in the classroom and in their social life.' (geciteerd in Hildebrandt, 2005: 75).

Nieuw rechts heeft in de jaren negentig vervolgens de term 'politiek correct' van zijn politieke vijand overgenomen en begon vaak zonder veel humor jacht te maken op nieuwe

\footnotetext{
${ }^{12}$ Zie de rol van Fox News en New York Post; McKnight 2012, hoofdstuk 8.

${ }^{13}$ De Groene Amsterdammer, 14 mei 2015.

${ }^{14} N R C, 19$ februari 2015.
} 
dogmatici ('fascism of the left', 'Sovietization of intellectual life'). Ook de term Gedachtenpolitie, een evocatie van Orwell's 1984, werd voortaan tegen links ingezet. Dat was niet zonder reden. Op Amerikaanse universiteiten werd geageerd tegen kwetsende taal gericht tegen minderheden en zouden alle mogelijke krenkingen buiten de deur moeten worden gehouden. Woorden als nigger, queer en cripple mochten niet meer benut worden. Iedereen verdiende a priori respect. Er werd een nieuwe orthodoxie opgelegd die discussie en communicatie onmogelijk maakte omdat niemand iets verkeerds wilde zeggen. Er ontstond een collectieve angst om voor racist te worden uitgemaakt.

De politiek correcte beweging poogde dus stigmatiserende taal in de taboesfeer te trekken: neerbuigende termen voor vrouwen, homo's en vreemdelingen werden niet meer geduld. Het controleren van stereotypen heeft zich vervolgens uitgebreid over de opleidingen en professies: zwarten mogen niet als dansers of sporters worden geportretteerd, vrouwen niet als thuiswerkers of moeders. Daarachter gaat een identiteitspolitiek schuil: studenten zouden zich vooral met de eigen culturele tradities dienen te identificeren. In termen van Todd Gitlin, een van de voormalige leiders van de New Left beweging: 'The oddity is that the Left, which once stood for universal values, seems to speak today for select identities, while the Right, long associated with privileged interests, claims to defend the common good' (geciteerd in Hildebrandt, 2005: 510). Identiteitspolitiek mondt volgens hem uit in zelf-segregatie, isoleert minderheidsgroepen van elkaar, en leidt tot verminderde tolerantie omdat vooroordelen voortaan als legitieme cultuureigen opvattingen door het leven kunnen gaan.

Rechtse houwdegens lachten zich een ongeluk over zoveel absurditeiten en gingen hals over kop pleiten voor maximale vrijheid van meningsuiting. Dat laatste is opmerkelijk omdat evangelisch rechts en communistenjagers als McCarthy de naam hadden om mensen te vervolgen wegens 'afwijkende' of 'subversieve' meningen. Aanvallen op de Amerikaanse eer ('Amerika heeft de oorlog in Vietnam verloren') werden en worden het liefst onder de radar gehouden. Conservatieven zijn van nature afkerig van satire, althans voor zover loyaliteit aan gezag voorop staat. Links daarentegen heeft altijd tegen heilige huisjes aangetrapt.

Het publiek was in ieder geval getuige van een amusante rolverwisseling: conservatieven gingen voor de First Amendment pleiten, terwijl links juist een rem op het vrije woord zette en een taalorthodoxie van anders-geaarde en anders-competente mensen ging benutten, een verbale hygiëne die met een ruime boog om sociale problemen heen liep (Hughes 2009: 24). Die rolverwisseling heeft rechts grote voordelen gebracht. Je kon het publiek makkelijk voor je winnen door je als 'vrij, open en fair' te etaleren en je af te zetten tegen iedere gedachtenpolitie. De strijd tegen politieke correctheid was niet alleen electoraal aantrekkelijk ('trashing the left') maar werd tegelijk een lucratief marketing-product. De populaire conservatieve boekserie The Politically Incorrect Guide is daarvan een mooi voorbeeld. Rechtse showmasters op radio en tv bestempelden hun programma's steevast als politiek incorrect en er werden T-shirts in de handel gebracht met teksten als 'Politically Incorrect. Free Minds, Free Markets, Free Society'.

Nog altijd wordt de politiek incorrecte vechtformule benut, niet alleen in Amerika maar ook hier. Populistische partijen maken er met voorliefde gebruik van: elke provocatie of beschuldiging verzekert media-aandacht en een voorsprong in termen van daadkracht. Het verwijt van censuur en zelfcensuur komt nu van rechts. Iets voorschrijven of verbieden heet voortaan 'links'. Libertair en liberaal rechts ageert - hoe wonderlijk - tegen fatsoen en is 
pionier geworden van de 'alles moet gezegd'-formules. Rechts nam daarmee de definitiemacht van taboe-doorbrekers in handen en kon links blijven verwijten om de hete brij heen te draaien en zaken toe te dekken.

\section{Het racisme-taboe en de populistische backlash}

Socioloog Herman Vuijsje signaleerde in de jaren negentig dat het racismetaboe aan intensiteit en reikwijdte had gewonnen en 'hoeksteen van de officiële moraal' was geworden (Vuijsje, 1996: 27). Hij wees er op dat de uitdijing van het etnisch taboe bevorderde wat men had willen vermijden: immigranten werden ongewild behandeld als leden van een hulpbehoevende etnische groepering en autochtone Nederlanders werden gestereotypeerd als latente racisten. "Ze zagen zich gesteld voor een double bind: ze moesten het andere tot iedere prijs respecteren, maar tegelijk mochten ze nauwelijks laten blijken dat ze het verschil überhaupt opmerkten. Binnen dit politiek correcte keurslijf werd elke verwijzing naar verschil, hoe aardig ook bedoeld, al snel als aanstootgevend ervaren" (Vuijsje, 1996: 27). Ook nu, twintig jaar later, laaien discussies over (vermeend) racisme nog altijd op. Soms benutten politiek incorrecte sprekers - in hun drang om te zeggen waar het op staat - al dan niet bewust racistische toespelingen. Het betichten van racisme brengt vervolgens weer veel mediaspektakel voort. Voor de massamedia is het uitmelken van identiteitspolitieke thema's van zwarte Piet tot minaret - sowieso een garantie voor hoge kijkcijfers.

Dat illustreert dat het racismetaboe inderdaad de kern uitmaakt van de officiële moraal. Binnen instituties als school, bedrijf en politiek kunnen etnische vooroordelen niet meer onbekommerd worden geventileerd. Het is dodelijk voor je reputatie om 'anderen' op grond van hun geaardheid openlijk te kleineren. Die disciplinering verloopt moeizaam voor mensen die gewend zijn stoere straattaal te bezigen. Zo hebben jonge macho's op het werk of op school minder mogelijkheden om vrouwen en vreemdelingen op hun plaats te wijzen. Niettemin, discriminatie en seksisme zijn deels 'ondergronds' gegaan en lijken nog altijd een vitaal bestaan te hebben in de private sfeer, maar uiteraard ook in cafés en op straat. Populisten spelen herhaaldelijk in op dit reservoir aan onvrede om 'geknechte' groepen aan zich te verplichten. Voor velen komt de tegenreactie van opiniemakers die 'zeggen waar het op staat' en uitvaren tegen elites, hoger-opgeleiden en deskundigen, als geroepen.

Sterker, sommige media zijn een libertair populisme gaan exploiteren waarin talkshow-hosts met elkaar wedijveren om incorrecte uitspraken te lanceren. Dat is een van de kernbevindingen van The Outrage Industry (2014), een onderzoek naar de woedende retoriek van radio en tv-populisten (denk aan de The Rush Limbaugh Show en The O'Reilly Factor) en de doorwerking ervan onder de Amerikaanse bevolking. Volgens de onderzoekers, Jeffrey Berry en Sarah Sobieraj, bieden dergelijke programma's waarin voornamelijk gelijkgezinde hosts en fans aan het woord komen een veilige politieke plaats aan een conservatief publiek dat zich verlaten en bedreigd voelt. In dergelijke shows waarvan alleen al het Fox netwerk er vele aanbiedt, krijgen zij de verzekering dat hun mening juist is, dat politieke tegenstanders naïef, dom, immoreel en 'unpatriotic' zijn, en ervaren ze een authentiek, gemeenschappelijk moment dat vooral gemoedsrust en comfort brengt. Het conservatieve publiek raakt even verlost van de moeizame face-to-face contacten in instituties waarin je steeds op je hoede moet zijn, je tolerant moet gedragen en je snel van racisme beschuldigd kunt worden. Veel 
psychologische studies wijzen uit dat er een 'witte angst' is om als racistisch en intolerant te worden gezien (Berry \& Sobieraj, 2014: 145). Vooral conservatieven voelen zich machteloos en niet in staat zich tegen (mogelijke) beschuldigingen te verweren. In woorden van de auteurs: 'the fear of being perceived as racist looms over the conservative respondents in the sample' (idem: 149).

Volgens de auteurs kan dat het succes van de woede-industrie en de grote conservatieve dominantie in talkshows verklaren. Een soortgelijke interpretatie lijkt op de Nederlandse situatie van toepassing. Ook hier zien we een backlash van (geregisseerde) woede en verontwaardiging, in de Telegraaf maar vooral bij PowNews en GeenStijl. Veel mensen voelen zich ongemakkelijk over migratie en menen dat hoogopgeleide progressieven met een grote boog om de problemen heen lopen. Op websites als GeenStijl wordt hun zogenaamde verdraagzaamheid als hypocrisie ontmaskerd. De onverschrokken 'benoemers' van die hypocrisie en verwante linkse misstanden (ontwikkelingshulp, etc) gaan vervolgens als morele helden door het leven. $\mathrm{Zij}$ die kwetsen en beledigen helpen de samenleving immers verder. PowNews en Geen Stijl bieden een veilige omgeving waar je de schijn van verdraagzaamheid niet hoog hoeft te houden, geen ballast hebt dat je op je woorden moet passen, ongeremd verbaal kunt 'leeglopen' of 'losgaan' en een aangenaam gevoel hebt onder verwante geesten te vertoeven. De open intolerantie geeft een zucht van verlichting, bevrijd uit het keurslijf van beschaafde hypocrisie.

\section{Slot}

Het politieke en sociaal-culturele definitiemonopolie ligt na de jaren tachtig bij rechts. Populisten nemen vaak met verve de rol van taboe-doorbreken en ontmaskeren op zich. Die politiek incorrecte houding past natuurlijk niet bij de rechtse hang naar orde en gezag, maar is retorisch te aantrekkelijk om op te geven. Een flinke aantijging of beschuldiging en alle deuren van de nieuws- en amusementsindustrie gaan open. Libertair en liberaal rechts is nu in veel opzichten vertolker van een anti-institutioneel ethos dat door links in de jaren zestig op de agenda werd gezet. Dat heeft overigens wel consequenties: de culturele definitiemacht van politiek rechts kan niet meer gevestigd worden op orde, deugdzaamheid en de klassieke humaniora.

Zoals uiteengezet, rechts is pleitbezorger geworden van 'alles zeggen'. Libertaire agitatoren neigen ertoe 'meningen voor je houden' als een vorm van lafheid te bestempelen waardoor de vurig verlangde vermenigvuldiging van godslasterlijke teksten of prenten uitblijft. Deze taboe-bevechters lijken op die manier hun eigen taboes te scheppen. Zo kan het gebeuren dat het recht om te beledigen als 'heilig' wordt bestempeld. Binnen dat denkframe krijgt elk verbod of elke zelfcensuur de reuk van onreinheid. Sommige tekenaars lijken doldriftig op oorlogspad: de tegenstander een lesje leren, intimideren of neerhalen. Net als polemisten en volkstribunen wordt gezinspeeld op morele superioriteit: 'zij' zijn kleingeestig, doortrapt of achterlijk, 'wij' zijn vrijzinnig. Er zijn echter - zoals cartoonist Rowson aangeeft - goede redenen voorhanden om een prent niet te publiceren: te dicht bij propaganda of louter vuilspuiterij. Tegelijk, zegt Rowson, is het niet de taak van cartoonisten stichtende kost te bieden of uit te nodigen voor een vergelijk. Het gaat om het aftasten en overtreden van morele grenzen. 
Hoe verhoudt zich dat tot 'het wezen van de democratie'? Stel dat we minder gebruik zouden maken van bijtende en agressieve vormen van spreken. Dat zou het rijk van uitingen ongetwijfeld armoediger maken, maar betekent nog niet dat de democratie veel veren laat. Meningsvorming is aangewezen op kennis nemen van feiten en ervaringen vanuit uiteenlopende perspectieven en het afwegen wat nodig en wenselijk is. Het in ongerede raken van die communicatie zou pas werkelijk fataal zijn voor de democratie.

De retoriek van 'escalatie van godslasterlijke cartoons' en in een adem door 'de citadel van vrije meningsuiting staat op het punt het te begeven' leert dat het speelveld waarop cultuurstrijd plaatsvindt bezaaid is met hele en halve taboes en dat vertolkers van maximale uitingsvrijheid allerlei vermaningen en verplichtingen tevoorschijn toveren. Overal waar opinies worden opgetuigd tot onaantastbaar, worden taboes gecreëerd.

Ogenschijnlijk gaat het om een anomalie omdat in de moderne seculiere samenleving niets strikt verboden zou zijn. Zo heeft obsceniteit veel zijn oorspronkelijke betekenissen van beestachtig, walgelijk, vies of wellustig verloren. Onfatsoen lijkt zelfs een overleefd begrip te zijn. Taboeonderwerpen leiden echter nog steeds tot boosheid, gechoqueerde gevoelens, verbijstering en zelfs hysterie. Zo raakt het claimen van aangeboren etnische verschillen meer dan ooit een open zenuw.

De politiek correcte beweging heeft de samenleving niet overstelpt met verboden zoals het verhaal wil. Wel hebben voorstanders van correct taalgebruik bijgedragen aan een valse omzichtigheid in het debat en de verbreiding van een overgevoeligheid voor mogelijke kwetsuren. Zij hebben ook bijgedragen aan de opkomst van een identiteitspolitiek die minderheden in de waan liet dat eigen tradities voorbeeldig zijn. In de huidige lawaaiige, politiek incorrecte cultuur waarin vooral religie op de korrel wordt genomen, waait een heel andere wind. Niettemin blijven ook in die cultuur taboes hun kracht behouden, ook het racismetaboe. Zoals de socioloog Wouters zegt: in een democratische samenleving zijn noties als 'wij zijn betere mensen' en 'zij zijn inferieur' naar het rijk van de verbeelding en van sport en spel verbannen. Tegelijkertijd behouden die noties op straat en in het café hun vitaliteit.

\section{Literatuur}

Allan, K \& K. Burridge (2006), Forbidden words, Taboo and the censoring of language, Cambridge University Press.

Berry, J.M. \& S. Sobieraj (2014), The Outrage Industry. Political Opinion Media and the New Incivility, Oxford University Press.

Dean, Malcolm (2013), Democracy under attack. How the media distort policy and politics, Bristol: The Policy Press.

Hildebrandt, Mathias (2005), Multikulturalismus und Political Correctness in den USA, Wiesbaden: Verlag für Sozialwissenschaften.

Hughes, Geoffrey (2009), Political Correctness: A History of Semantics and Culture, WileyBlackwell

McKnight, David (2012), Murdoch's Politics, London: Pluto Press.

Rolfe, Mark (2008), Clashing Taboos: Danish Cartoons, the Life of Brian and Public

Diplomacy, The Hague Journal of Diplomacy 4: 261-281.

Rowson, Martin (2009), Dark Magic, Index on Censorship, 38 (1): 140-164 
Stokkom, Bas van (2008), Het vrije woord als fetisj. Mondig tegen elke prijs. Den Haag: BJU. Stokkom, Bas van (2013), Mediaschandalen en punitief populisme, Strafblad 11 (5): 371-380 Vuijsje, Herman (1996), Correct. Weldenkend Nederland sinds de jaren zestig, Amsterdam: Contact.

Wouters, Cas (2008), Informalisering. Manieren en emoties sinds 1890, Amsterdam: Bert Bakker. 